\title{
Evaluating Community-Based Research: Hearing the Views of Student Research Partners
}

\author{
*Mark Cullinane and Siobhán O'Sullivan, School of Applied Social Studies, University \\ College Cork, Republic of Ireland \\ Contact: $\underline{\text { mcullin@gmail.com }}$
}

\section{ABSTRACT}

Despite the increasing popularity in the academy of collaborative approaches to research, evaluating the impacts of Students-as-Partners (SaP) initiatives has thus far received less systematic attention. This paper presents an evaluation of a participatory community-based research project where academics partnered with 15 mature students in a socio-economically disadvantaged estate in the south of Ireland to co-construct a household survey and conduct field research to gather the views of fellow residents on the regeneration of their area. The paper reports the findings of a subsequent qualitative, participatory evaluation of the student's experience of this partnership with academics and its impacts. The findings illuminate some of the benefits and challenges of community-based staff-student research partnerships and points to the imperatives of aligning institutional, funder, and community participants' capacities and objectives throughout the research cycle and the importance of evaluation to inform good practice in community-based research.

\section{KEYWORDS}

students as partners, evaluation, university outreach, community-based research

Students as Partners ( $\mathrm{SaP}$ ) is an emerging discourse and set of practices that seeks to "engage students and staff as collaborators on teaching and learning endeavours, establishing collegial working relationships based on reciprocity, mutual respect, shared responsibility, and complementary contributions" (Marquis, Black, \& Healey, 2017, p. 720).

For Brew (2013), this comes against the background of an increasing emphasis in higher education on the desirability of involving undergraduate students in original research and inquiry, around which a proliferation of models and frameworks have emerged. She suggests that this shift towards a view of the student as producer rather than mere consumer of knowledge (Neary, 2010) arises as part of a broader reorientation of the academy in response to the complexities and ambiguities of twenty-first century society, including numerous global societal challenges and the increasing contestation of traditional knowledge bases. 
Whilst staff-student research partnerships have become a recent emphasis within the Scholarship of Teaching and Learning (SOTL), in the social sciences and adult education fields - the disciplinary and institutional loci of the research partnership detailed in this paper-there has long been a focus on collaborative work through community-based and participatory research. As with SaP initiatives more broadly, these inclusive forms of research are differentiated in terms of scale, aims, methodologies, and the division of labour and power between partners across the lifecycle of projects (Goodson \& Phillimore, 2012). However, such approaches share a focus on involving and "engaging community members as co-researchers" (Goodson \& Phillimore, 2012, p. 4) in co-creative processes, placing at the centre of the research process and aiming at the empowerment of "those people whose life-world and meaningful actions are under study" (Bergold \& Thomas, 2012, p. 2). Such research may aim toward the production of knowledge in order to better understand a community or issue(s) and may additionally aspire to "stimulate action-oriented outcomes and policy change" (Goodson \& Phillimore, 2012, p. 4).

As Bovill (2017) observes, discussions around who participates in SaP initiatives, and when, have often emphasised the value and necessity of enhancing the inclusion of hard-toreach students as well as previously excluded groups. This points to the complementarity between SaP approaches and the "democratizing aims of adult education" (Joyappa \& Martin, 1996, p. 1). Indeed, Zhu (2019) notes the use of participatory research methodologies in adult education since the 1970s and the shared philosophical foundations and commitments of adult education and the Participatory Action Research (PAR) methodology. Both share a commitment to education for social change, emphasise individual and collective empowerment, and challenge prevailing paradigms in both teaching and social science research methodologies.

Today, as the broader social responsibilities of universities-particularly with regard to persistent educational inequalities - are being increasingly highlighted and problematised (e.g., O'Sullivan, O'Tuama, \& Kenny, 2017), co-creative methodologies are being adopted and promoted by universities as part of their strategies of civic and community engagement. These are often delivered under the rubric of adult education as well as through the Science Shop model (Leydesdorff \& Ward, 2005).

Research assessing the practical value of student-staff partnerships has identified a range of benefits that may accrue to the involved parties (Mercer-Mapstone et al., 2017). These include the deepening of learning through engaging a diversity of perspectives, enhancing staff and student motivation, and developing greater trust between teachers and learners. They may also contribute to the democratisation of learning, and in so doing provoke shifts in self-understandings of the roles and identities of students and educators alike (Marquis et al., 2017; Matthews, Dwyer, Hine, \& Turner, 2018). These potential benefits align with the economic, social, and personal benefits associated with adult learning and community education, including more positive mental health, enhanced social networks, greater political and community participation, and intergenerational improvements to educational outcomes (Machin, 2006). Such potential outcomes also reflect the ways in which the practice of undergraduate research generally addresses "ontological aspects, such as changing the being of students, developing their personal and professional capabilities and influencing their perceptions of themselves" (Brew, 2013, p. 604).

However, scholarship in the area has also identified a range of challenges to effective and mutually beneficial research partnerships between education professionals and 
students (Mercer-Mapstone et al., 2017). These include a lack of fit between the democratising ethos of SaP initiatives and exclusionary practices of selection in predominantly hierarchical and socially stratified educational institutional cultures (Felten et al., 2013), alongside concomitant resourcing and time constraints which may undermine the depth of partnerships as well as the extent of their inclusivity (Marquis et al., 2017). They also include the challenges of negotiating power relations in partnership processes and overcoming scepticism of staff and students alike about the potential benefits of "involving students more fully in learning and teaching" (Bovill, 2017, p. 3). Scholarship on communitybased research has emphasised the appropriate treatment and remuneration of community researchers as a key concern (Goodson \& Phillimore, 2012), as well as the imperative to find ways to foster "longer term alliances or partnerships" (Bell, Addy, Madew, \& Kainulainen, 2012 , p. 94) with communities involved in research. These issues are particularly salient in relation to communities characterised by high levels of socio-economic disadvantage that often become a sustained focus of social scientific research.

Yet, despite the extensive body of literature on collaborative approaches to research, evaluating the impacts of staff-student research partnerships has thus far received less systematic attention (Goodson \& Phillimore, 2012). Studies to date have tended to focus on the challenges and facilitating factors to partnership which, while valuable, neglect outcome measures and the development of evaluation frameworks (Faridi, Grunbaum, Sajor Gray, Franks, \& Simoes, 2007). Most research conducted on community-based participatory research focuses more on processes rather than outcomes and impacts (Piggot-Irvine, Rowe, \& Ferkins, 2015; Faridi et al., 2007); this is similar in research to date on students as partners (Ahmad et al., 2017; Coombe, Huang, Russell, Sheppard, \& Khosravi, 2018) although Curran (2017) focuses on impact in terms of personal development and enhancement of the learning climate.

This paper presents the first findings from an evaluation of a participatory research initiative conducted with the collaboration of university staff and a group of non-traditional mature students from a neighbourhood in Cork City, Ireland that is currently undergoing extensive regeneration of its large social housing stock. This paper focuses on the students' experience of partnership with academics from their own point of view-including both positive and negative dimensions of partnership-and assesses what difference their engagement in the project made to them. In so doing, it aims to contribute to the broader literature on the effectiveness of staff-student research partnerships in general and in the particular context of adult education and university outreach initiatives in areas characterised by socio-economic disadvantage. It also aims to respond to specific lacunas in SaP and SoTL research. These include a lack of clarity on the extent of inclusiveness and diversity in SaP work, given the finding of Felten et al. (2013) that "socio-cultural or other demographics of student participants or partners" is often omitted in accounts of SaP initiatives (p. 64), a finding supported by a recent systematic review of empirical SaP literature by Mercer-Mapstone et al. (2017). This paper also responds to the finding in the same systematic review of an undue tendency in the literature to focus on positively oriented outcomes to the detriment of accurately reflecting the ambiguities, conflicts, and sometimes messy realities of partnerships.

\section{Background to the research partnership}

In 2014, Cork City Council commissioned the School of Applied Social Studies in University College Cork (UCC) to evaluate the implementation of the Cork City Northwest 
Quarter Regeneration (CNWQR) Masterplan. The CNWQR programme involves the demolition of 450 houses and their replacement by 656 new housing units in Knocknaheeny. This is one of the most disadvantaged areas of the city characterised by high levels of deprivation and unemployment (Central Statistics Office, 2017). Whilst the area also has lower levels of formal educational attainment in comparison to the rest of the city, there is also a well-developed community and adult education infrastructure in Knocknaheeny and its northside environs as well as a strong sense of local identity and social cohesion (Respond! Housing Association, 2014).

Following negotiation with the project funder, it was agreed to incorporate a participatory research component to the Masterplan evaluation. In fulfilment of this, in 2015 three academics co-designed a household survey with 15 mature students (see acknowledgements below), most of whom who were enrolled in a community-based, parttime women's studies diploma programme. This intergenerational group of students, whose age profile ranged from late thirties to early seventies, were all residents of Knocknaheeny and included a number of participants with close familial relationships to each other, including a mother and daughter. The group's composition reflected mixed previous experiences of formal education and included some early school leavers as well as many with prior community and further education experience, as well as a number with higher education qualifications. Many of the group had extensive experience of contributing to their community through volunteering and local activism.

This programme was offered as part of a pilot outreach access partnership between Adult Continuing Education (ACE) in UCC, the Cork Education and Training Board, and Cork City Partnership. For the survey, the student partners undertook a specially devised module (equivalent to 5 credits in the standardised European Credit Transfer system) on "Research in the Community" and through a series of workshops facilitated by the academics in a community space, they co-designed the questionnaire. Over a period of ten weeks, the student partners became community researchers and gathered the views of nearly 500 households in the community on topics relating to the ongoing regeneration process. This reflected an overall survey response rate of $72 \%$. The survey data was subsequently analysed by the academic research team only, as although invited to contribute to this process, the student partners did not do so due to the significant time commitments they had already made to this voluntary project. Its findings were then collectively explored in a meeting convened in February 2016 involving the staff and student partners and the Cork City Council regeneration team. Later, key findings were compiled by the staff researchers and distributed by the Council in a community newsletter to all households in the area, and two follow-up focus group meetings were held by the Council with a sub-set of residents in one part of the area in 2016 and 2017.

\section{EVALUATION METHODOLOGY}

In 2019, an evaluation was undertaken involving a majority of the same cohort of mature students involved in the survey design and fieldwork in order to ascertain their views on what had worked well about the project, how satisfied they were with the partnership with the academic staff, and what difference the project made to them (as asked by Vortruba, 1996). Consistent with the survey, the evaluation also drew on a participatory methodological approach, incorporating "user engagement in determining, designing and analysing research questions and approach" (Johnson et al., 2019, p. 17). To this end, a focus group was initially held with five of the original student partners to help 
inform the areas of focus for the evaluation interviews. Qualitative semi-structured interviews with an average duration of just over thirty minutes were subsequently held with 10 student partners (comprising two-thirds of the full group originally involved) in the local community centre and were undertaken by a researcher unconnected with the original project.

Interviews were subsequently manually transcribed, facilitating an inductive thematic analysis of data (Braun \& Clarke, 2006) from which an overall picture of interviewee perspectives was attained. Interview material pertaining to each of the main discussion topics were first manually coded. Coded interview data for each topic then was collated and examined as a whole, from which interview quotes representing and illustrating themes were selected for inclusion according to their relative prevalence. The main findings of the interviews-anonymised using pseudonyms-are reported and discussed below. These are structured according to the main interview discussion topics, which explored with student partners their initial motivations for getting involved with the project and expectations around it, the ways they felt they influenced the design of the research and its implementation, and how they viewed the experience of partnership with the academic staff. The interviews also explored their perspectives on project outcomes, their suggestions on how future community-based research of this nature might be undertaken, as well as their reflections on the personal significance of their involvement in the project and the broader impacts of their experience in the adult education programme. A draft of the full paper was shared with the student partners prior to submission for general input and to help maximise the accuracy and representativeness of the findings reported.

FINDINGS

\section{Getting involved}

Asked about their motivations for getting involved in the participatory research project, the student partners emphasised the existing coherence of the group as classmates, their own interest and sense of stake in the topic of local housing regeneration, and the view that community members, for pragmatic as well as ethical reasons, should play an active role in research about their community.

Eleanor reported that the group agreed to get involved as they collectively saw the value to the research of their knowledge of the community, explaining that "because we knew each other, we knew the places, ... we knew because most of us were from the area, that it would've been easier for us to do it as opposed to strangers coming into the area."

Many of the student partners emphasised that the topic of the regeneration scheme was a "live issue" within their own community, spurring their own curiosity about learning more about it and the views of other community members. As Claire put it,

we were a very strong group, and because it was regeneration in our own community, it was very important to certain people in our group because they were living in the regeneration themselves, but because I was so involved in the community here, like it happened before my eyes.

Beyond this, some of the group reported that they were motivated in part by the hope that the project might yield practical benefits for the community. For example, Nora 
expressed the initial hope that the work might "help ... the area", whilst Liz emphasised that she had envisaged the information to be gathered from the community as "hugely important to the community itself."

\section{Training and research design}

The student partners offered positive evaluations of the experience of participating in workshops with the academic staff on the design of the survey questionnaire and the protocol for undertaking the door-to-door fieldwork. They emphasised the high quality of facilitation, sense of authentic collaboration, and level of support and preparation.

Máire, for example, reported a strong sense of mutual respect and meaningful input into the research design between the staff and student partners, saying: "when it was all being put together and you know, when we were all in the group doing the work, we were all treated like... like our input was important and what we were doing was important and appreciated."

Roisín spoke about the collaborative process in effusive terms as a "fantastic" and even as a "magical experience." This was attributed to her sense that the staff and student partners had, as a collective, successfully taken advantage of the "intelligence of all the women that were involved in putting this together" who had "really came out with the very, very important details that we felt as women up here that we needed to ask." A number of the student partners were, however, more circumspect about whether the collaborative process had yielded a satisfactory research instrument, including Nora who reported feeling "from the start" that too much information was being sought from residents and often in an overly complex manner.

That said, several of the student partners felt that one of the key contributions made by the group in the research design phase was in helping to bridge the gap between academic language and the local vernacular. Another contribution lay in helping to add a measure of "real common sense" to the project and its approach. As Margaret said:

You have UCC [university] speak, and you have our speak. I'm not putting one down or one up, right? But you need our speak to go around, because if I was using UCC speak, they'd say what are you on about, you know what I mean, it'll put people's hackles up.

Áine similarly commented on how the group were able to "give our input on the way the questions were put." Sandra felt that the academic facilitators "appreciated that, because there's an awful lot of, say, on-the-ground knowledge that they didn't know."

One aspect of on-the-ground knowledge that the student partners emphasised was the extent of community anxieties about the regeneration, which many of the group evidently shared or empathised with themselves. These included concerns about the protracted duration of the multi-phased regeneration process and its impacts on people's lives, perceptions of communication deficits on the part of the regeneration authorities with the broader community, and differing perspectives around the desirability of wholesale housing demolition as a substitute for refurbishment programmes. The extent of such concerns engendered for some of the student partners a trepidation about engaging with the broader community on the regeneration process, including Carmel who reported feeling "worried in case people weren't going to co-operate with the survey." Nonetheless, she reported that the collective planning around the fieldwork protocols meant that the group 
members "were made very comfortable about what we were going to ask" on the doorsteps.

\section{Fieldwork}

When commenting on their experience of conducting the fieldwork, the student partners reported enjoying the sociability of being paired up with a colleague and going door-to-door engaging with others in their community. Liz, for example, commented on how she enjoyed "being with the women so much, I love being out in the community, I love talking to my neighbours," while Carmel spoke about enjoying meeting up with her allocated partner and "being able to provide backup to each other" if they encountered any challenges on the doorsteps. Others enjoyed the fieldwork less, with several pointing out the time-consuming nature of the process, particularly given the need to make return visits to households in the interests of maximising the survey response rate.

An issue frequently raised by many of the student partners was that the closed questionnaire format itself created challenges at the doorstep. In particular, some of the partners felt that the completed questionnaire was too long, repetitious, too reliant on scaled-response questions and, above all, didn't afford the opportunity to qualitatively capture the perspectives of residents. For example, Margaret reported how in some instances she observed "people's eyes were glazing over in a sense, on the doorstep" owing to the question format. Eleanor reported how although many of those they surveyed were keen to talk about the issues in relation to the regeneration as they saw them, she felt that "I just don't know if they got to the bottom of, like, how people really felt" as "we had nowhere to write it down." Despite this key shortcoming, most student partners nonetheless felt that, like Claire, the survey "captured a little glimpse" of relevant issues and that the survey nonetheless "worked" within its limitations.

The student partners were strong in the overall view that their belonging and embeddedness in the community was a significant asset to the project in terms of the efficacy of data collection. In particular, many of the group volunteered the view that their visibility in the community-whether they were known personally or not-often contributed to the comfort of residents to firstly open their doors to the student partners and secondly to participate in the survey. Eleanor, for example, commented how "if people recognised you, they're more kind of willing to talk to you. If it's somebody that they don't recognise they mightn't even open up the door."

Áine pointed to the advantages of the intergenerational nature of the group in contributing to this reception, saying it was good to have some older members of the group involved in the fieldwork who "would've been close to a lot of the people living there."

Roisin suggested that knowing that they were speaking to people in similar living situations encouraged honesty and frankness amongst respondents, saying, "I felt that they were truthful in a lot of ways about the houses [because] they knew I was living in a similar house with the [same] problems that were there."

Liz similarly felt that because the "whole community is disadvantaged," the affinities between the researchers and the researched were readily recognised because they were "in the same situation, you can relate to them and they can relate to you."

However, some of the student partners also saw some downsides to their close geographical and social proximity to the community being researched. For example, Liz and Claire identified being recognised and familiar to people as an impediment to getting the work done expeditiously. This meant that "you could be all day on the doorstep" according 
to Liz, which for some was a frustration given their volunteer status. The student partners were also occasionally exposed to challenging interactions. Eleanor recalled an instance of a woman whom she was surveying who became upset while discussing her housing situation, which Eleanor described as an upsetting interaction that had troubled her afterward.

More broadly, what Liz described as the "huge fear" in a disadvantaged community like theirs towards officialdom was sometimes reflected in residents' reactions at the door. Eleanor, for example, said her uncertainty of how the survey might be received by local residents meant she had been "still kind of nervous going to the door." Roisín attributed this to community anxieties about the protracted duration of the regeneration process and uncertainties about their own potential move of home. Because people were "so anxious, because they're after waiting so many years, and there's so many setbacks going on down the line that it's just, that's all they're going to look at." Claire pointed out that, for many residents, the survey was likely to have been the first time they had been directly approached on their doorsteps and invited to share their views.

\section{Outcomes and impacts}

For many of the student partners, a sense of pessimism pervaded their commentary on the survey's outcomes and impacts and the extent to which the research, more than three years later, had made a difference on the ground. This was exemplified by Carmel's comments, who, perceiving an absence of any evidence to the contrary, gave a negative assessment of the likely impact of the survey, saying "we don't know what the outcome of this, we don't know how it was handled, was it put on the back burner, and we just done the survey and that was it." Máire said that to her knowledge, "none of the issues that [survey respondents] would've pointed out to us would've been resolved." Sandra suggested that this was likely to further concretise the views of many in the community who felt that they had no real voice in the regeneration process.

For Sandra, this sense of inefficacy was additionally problematic because their involvement was personal and voluntaristic rather than professional: "it wasn't a job for us, we did it because we were interested ... and we wanted to give something back ... and we never found out ever what happened."

Further, what was felt as a sudden end to their involvement in the project after the completion of the fieldwork led to her feeling not only "a bit disheartened" but also somewhat exploited:

What I felt myself was maybe that, we... we got [you] to do a very important project, that we benefited from, that saved us paying staff to do, and now we have all the information, so you're surplus to requirements.

For Liz, the sense of inefficacy was ultimately rooted in structural reasons relating to local authority governance and funding. She expressed concern that the survey was destined to be a "cosmetic exercise" and unlikely to meaningfully "inform the Council" simply because the broader funding picture for housing and local services provision in Ireland remained nationally centralised and in dysfunction.

Several members of the group were more positive about the survey's impacts, including Máire's expression of optimism that the regeneration authorities were listening and that the survey's findings would likely meaningfully inform their future plans-albeit that it would only be in the long run that any impacts would be visible on the ground. Roisín 
reported that she'd like to think the survey had contributed to a greater openness and humility on the part of regeneration officials. Where before participating in the project she felt they had exhibited a very "matter of fact" attitude at community meetings, after the students did the survey, she felt the regeneration officials "started to listen to what people wanted, and what people needed, and took things seriously, is what I feel came out of that."

However, the student partners offered few specific recollections regarding the formal meeting between the student partners, academic staff, and regeneration officials in which the survey's preliminary results were presented and discussed. This is likely attributable in part to the challenges of information recall owing to the greater than threeyear interval between the completion of the research project and the evaluation, as well as the three-month period between the completion of the fieldwork and the presentation of findings to the regeneration authorities. During this time, the student partners had completed their formal studies, contributing to a lower attendance at the meeting.

\section{Personal benefits and learnings}

Notwithstanding a general sense of inefficacy of the research project in terms of tangible outcomes, the student partners reported a range of personal benefits arising from their contribution to the participatory research project. These included increases in personal confidence and self-esteem, the forging of new friendships, and learning not only about the theory and practice of research but also about their own community.

Several student partners, like Carmel, spoke about how contributing to the project had given her "great confidence in talking to people," including helping her to feel more comfortable with being interviewed for this evaluation.

Margaret described herself as having "thrived" in the project, saying she had "loved researching" and that she particularly valued the enhanced personal confidence and new friendships she had accrued through the experience. Áine noted her satisfaction with learning about and implementing research methodologies and how "it was good to know. . . how to set up one and how to ... go out and do one."

Sandra highlighted how the fieldwork contributed to a transformed personal perspective on parts of the neighbourhood about which she acknowledged having had negative "preconceptions" growing up. Through her engagement with residents on the doorstep, she reported learning a lot about the people, their housing situations, and their concerns, helping her overcome what she had come to see was an "insular" way of thinking about her area.

As someone who reported marrying young and who had many familial obligations, Roisin said that the project and the course of which it was a part represented important personal growth. It meant "finally doing something for myself, realising that I'm a human being and I have an important part to play in life," and the realisation that "I wouldn't go putting myself below people anymore, I'm as good as anybody else."

Liz summed up the benefits for the group as having "opened up the women" in different ways, including encouraging them to recognise their own skills, resilience, and achievements in the domestic sphere and challenging what she saw as entrenched workingclass perspectives on their unsuitability for higher education, which she viewed as a "huge" positive arising from their involvement. Sandra similarly spoke of the individual and collective commitment to themselves and their education that the course represented: "we're all so busy, we're working, we've families and stuff, and we made this time for 
ourselves, which we hadn't before. ... we wanted to go, it was for ourselves because we wanted to go there."

Nora reported the course as the "best thing [she] ever did," that she has "never looked back" since, and that it had spurred for her a greater political awareness and encouraged her to sign up to various courses locally. Whilst for Eleanor, the experience provided her with "the encouragement that [she] needed" to later apply for enrolment into a full-time third-level programme, which she subsequently successfully completed.

\section{Recommendations for future research}

Asked about what they would keep or change about a similar project if it were to be repeated, the student partners emphasised their desire for work of this nature to centre around the involvement of the community-those most affected by projects like the regeneration scheme. Claire emphasised that "the formula of getting people from the area . . . to be part of planning from early on gives them an input into how their community is and what it looks like."

Others like Nora pointed to the community-based setting of much of the course delivery as a positive and encouraging factor for their involvement: "Anything going on here makes it easy, because you just know everyone, and they're all so welcoming." Máire praised as positive the "mixture" of community-based and campus-based learning during the diploma, which she said was "good to open up people's eyes to what it was like to be in a college."

In addition to suggestions around methodological changes or additions, particularly the view that including more open questions in the survey would have been appropriate, the student partners offered a range of views on what could be done differently with this kind of work. These included the suggestion, offered by Liz, that debriefs be conducted with the fieldworkers when returning the completed surveys in order to "wind down and ... get things that people were saying off their chest."

The student partners particularly emphasised their desires for work of this kind to include more structured means of follow-up after the completion of the fieldwork and the production of research findings, for their benefit as well as the broader community. For example, Máire noted that she felt an expectation on the part of many of those they surveyed that participating would make a material difference: "when we were speaking to people, I think that they felt that doing the survey with us was going to result in something being done for the problems they were having in their houses." Áine emphasised that in a context where many in the community felt under-consulted and under-informed about the regeneration process, it was important to be able to effectively communicate to locals the purpose and outcomes of participatory processes, or "why did they do it, what was done with it."

Liz suggested that a project of this kind should ensure that a clear aim for some visible impact should be built into the project planning process itself. She said that it would be "hugely important" that there would be funding available to "make some type of change ... before I take on this research" to be able to have "something visible on the ground" and to show that "we're not just talking."

\section{DISCUSSION}

Taken as a whole, the retrospective evaluation by the student partners revealed a broadly positive, albeit qualified, appraisal of their experience as partners in this 
community-based participatory research project. They suggest a strong degree of overall satisfaction with the quality of partnership with the academic staff involved in the research training module and subsequent fieldwork, and a range of personal and collective benefits arising from their involvement in the project. Less positively, they revealed ambivalences and dissatisfactions in relation to aspects of the methodological approach and, in particular, a widely-perceived lack of overall project impact, over three years on.

These findings resonate with recurrent themes in SaP and participatory research literatures, as well as posing clear (though sometimes thorny) questions for SaP practice, particularly in adult education settings and when involving disadvantaged communities and statutory institutional partners.

Viewed as an example of university outreach, the personal and collective benefits accruing to the student partners may be seen as illustrative of the positive role that staffstudent research partnerships and community-based adult education can play in helping to diminish the boundaries between higher education institutions and communities characterised by multiple forms of disadvantage (O'Sullivan et al., 2017), in particular by challenging socio-cultural barriers to higher education (Harwood, O'Shea, Uptin, Humphry, \& Kervin, 2013).

Indeed, involving students as partners in this participatory research project was only made possible by the pre-existing networks between the community and the university via an ongoing community-based adult education programme. This drew its success in significant part from the organic links and strong relationships that had already been forged within the cohort of student partners, some of whom had got to know each other through involvement in other community-based trial or "taster" courses. These links were in turn enabled by the pivotal role played by Cork City Partnership in the recruitment and ongoing support of the student partners.

The evaluation findings suggest other strengths of the initiative. Satisfaction on the part of the student partners in relation to the course material, research design workshops, and fieldwork and their contributions to same indicate that the project design as a wholeand the division of labour between staff and students therein-was well-tailored to the expectations and capacities of the student partners. Methodologically, the high response rate and strong engagement at the doorsteps attained by the student partners in their administration of the household survey can be seen as illustrative of the contribution to research validity and quality made by the student partners, which was acknowledged as owing in part to their status as community "insiders" (Atfield, Brahmbhatt, Hakimi, \& O'Toole, 2012, p. 78).

Nonetheless, it is apparent that the project did not escape some of the challenges and pitfalls associated with university-led, community-based research. First, the apparent disconnect between the expressed motivations of the student partners and the format and methodology of the household survey can be seen in part as reflecting participatory disparities in the funding and design of academic research, including research that involves communities. In particular, it reflects the tendency for community involvement at the project proposal phase to be curtailed or absent (Blakey, Milne, \& Kilburn, 2012).

Concerns and ambivalences expressed by the student partners in relation to datacollection in the community on behalf of institutional authorities and the raising and dashing of community and student partner expectations around research impact underline the reality of the ambiguities and "blurred lines" (Atfield et al., 2012, p. 78) associated with the "insider" status of community researchers. This points to the need to sufficiently 
recognise throughout the research cycle "the implications of being involved in research for their ongoing relationships with those communities" (p. 84). This is particularly crucial when the research pertains to topics and involves sponsoring authorities where clear local sensitivities exist.

Ambivalences and disappointments expressed by the student partners around the overall value and broader utility of the research-including for some a sense of premature finality following the fieldwork - point to broader ethical and practical challenges in the management of discrete pieces of community-based research, particularly in projects that exist as voluntary adjuncts to part-time education programmes. These include questions about how to best approach trade-offs between maximising participatory depth at different stages of projects, methodological rigour, respecting the voluntary status of student partners, and maximising the long-term value for all partners to the research.

Such challenges remind us of the broader constraints within which university-led participatory research typically takes place, described by Mannarini (2012) as entailing the "dilemma of supporting bottom-up processes, emancipation and self-determination and at the same time of fulfilling the need for product, efficiency and effectiveness" (p. 143). These challenges also demonstrate how such constraints may be magnified where funding bodies and/or institutional partners involve statutory authorities, whose governance modes tend to respond more to the "functional logics of the administration more than to the capacities, interests and dynamics" (Parés, Bonet-Martí, \& Martí-Costa, 2012, p. 259) of local civil society. Such findings are illustrative of tensions common to undergraduate research more generally, such as those relating to whether the emphasis is placed more on the process of research or its outcomes, as well as who initiates a project and defines its scope, duration, and participative depth (Brew, 2013; Beckman \& Hensel, 2009).

The findings also point to ways such challenges could be addressed. For example, aligning the motivations and capacities of the community-based student partners with appropriate research methodologies highlights what Bell et al. (2012) describe as the imperative to "persuade funding bodies to support process-oriented community research" which places front and centre the "subjective experiences of the community and their learning processes" (p. 97). This is particularly apposite in the context of urban regeneration initiatives, where meaningful citizen participation has been identified as holding out the possibility of reorienting state-led regeneration in a more holistic direction. In particular, such participation can support a greater focus on social and community development, helping to correct a tendency to over-emphasise the "physical and economic aspects" (Parés et al., 2012, p. 256) of area redevelopment.

However, given that in this project the student partners also reported benefitting from their training and implementation of technical, quantitative research skills, part of the solution to these apparent methodological tensions and trade-offs may lie in the flexible application of approaches that validate both academic and experiential knowledge without prioritising either (Blakey et al., 2012). In this project, this may have been achieved to some extent through the greater use of open questions in the survey instrument.

To further support the student partners to assert ongoing ownership of their research after the formal end of a project, and to cater to differential levels of interest and capacity to contribute to various stages of research projects, including analysis and dissemination, McCarry (2012) proposes offering the option of "differentiated levels of involvement at the various stages of the research" (p. 64). Because involvement in the analysis phase in particular helps ensure that the analysis remains accessible and usable by 
the community "beyond the life of the research" (Blakey et al., 2012, p. 114), the importance of exploring creative and accessible ways of appropriately involving the community in the latter phases of research-even in a relatively small-scale and timelimited project-is underlined here (Atfield et al., 2012).

Lastly, responding to the ambiguities and risks associated with the student partners' "insider status" may have been accomplished in a small way during the data collection phase through the systematic provision of debriefs and other relevant practical supports while undertaking fieldwork in the community. More substantively, however, the findings indicate the imperative of adopting more empowered approaches within community-based research, in particular, building into research designs "community outcomes, which motivate community involvement, as an aim alongside academic outcomes" (Blakey et al., 2012 , p. 106). This would require an integrated approach throughout the research cycle, including ensuring the earlier involvement of the student partners in the framing and goalsetting of the research, situating such a project within a coherent local authority strategy for community participation in local regeneration, and prioritising better communication and demonstration of the reception, contribution, and impact of the research. Taken together, such measures would help mitigate the risks of community dissatisfaction with episodic academic research projects (Bell et al., 2012) as well as the "participatory fatigue" (Parés et al., 2012, p. 259) that can be engendered by participatory processes that merely offer what Gaventa (2002) described as "voice without influence" (p. 1).

The findings of this paper, in reflecting on the subjective experiences and outcomes of a research partnership with a non-traditional group of mature students, underlines the value of evaluating SaP work with those involved in it. Whilst building in project evaluation on an ongoing rather than retrospective basis (as was the case here) could have better supported a genuine "ethic of reciprocity" (Cook-Sather \& Felten, 2017) between staff and students, which is central to supporting the democratising ethos of SaP, the findings that were generated nonetheless point to ways in which student-partner concerns may be addressed in future projects. More broadly, the findings support the view that fully realising the individual and collective potentials of staff-student partnerships also depends on the extent to which such initiatives can be embedded more sustainably within and help transform the cultures of educational institutions and external organisational partners (Healey, Flint, \& Harrington, 2014; Mercer-Mapstone et al., 2017).

\section{ACKNOWLEDGEMENTS}

This evaluation was funded by University College Cork's Academic Returners Scheme. With thanks to Lorna Kenny, Prof Cathal O'Connell, Noreen O'Regan, Dr Seamus O'Tuama and all of the student partners for their participation in the project and their and valuable input in the drafting process: Brenda O'Donovan, Caroline O'Mahony, Deirdre O'Regan, Eileen Matthews, Fiona O'Hare, Helena O'Doherty, Karen O'Connor, Kim O'Shea, Maria Hopkins, Marion O'Sullivan, Marion Philpott, Mary McCarthy, Olivia Fox, and Sharon Philpott. 


\section{NOTES ON CONTRIBUTORS}

Mark Cullinane is a postdoctoral researcher in the School of Applied Social Studies, University College Cork, where he is a contributor to research projects on housing, homelessness, and urban regeneration.

Siobhán O'Sullivan is a lecturer in Social Policy in the School of Applied Social Studies, University College Cork. Her principal areas of work include community-based, participatory, and mixed-methods research with a focus on education and housing inequalities.

\section{REFERENCES}

Ahmad, A., Ali, A., VanMaaren, J., Barrington, J., Merritt, O., \& Ansilio, K. (2017). Partnership in practice: Implementing Healey's conceptual model. International Journal for Students as Partners, 1(2). https://doi.org/10.15173/ijsap.v1i2.3197

Atfield, G., Brahmbhatt, K., Hakimi, H., \& O'Toole, T. (2012). Involving community researchers in refugee research in the UK. In L. Goodson \& J. Phillimore (Eds.), Community research for participation: From theory to method (pp. 71-88). Bristol: Policy Press.

Beckman, M., \& Hensel, N. (2009). Making explicit the implicit: Defining undergraduate research. CUR Quarterly, 4, 40-44.

Bell, P., Addy, T., Madew, M., \& Kainulainen, S. (2012). Universities as agents in the empowerment of local communities in Germany, Finland and Russia. In L. Goodson \& J. Phillimore (Eds.), Community research for participation: From theory to method (pp. 89-104). Bristol: Policy Press.

Bergold, J., \& Thomas, S. (2012). Participatory research methods: A methodological approach in motion. Forum Qualitative Sozialforschung / Forum: Qualitative Social Research, 13(1). https://doi.org/10.17169/fqs-13.1.1801

Blakey, H., Milne, E.-J., \& Kilburn, L. (2012). Data analysis and community research: Capturing reality on housing estates in Bradford, UK? In L. Goodson \& J. Phillimore (Eds.), Community research for participation: From theory to method (pp. 105-119). Bristol: Policy Press.

Bovill, C. (2017). A framework to explore roles within student-staff partnerships in higher education: Which students are partners, when, and in what ways? International Journal for Students as Partners, 1(1), 1-5. https://doi.org/10.15173/ijsap.v1i1.3062

Braun, V., \& Clarke, V. (2006). Using thematic analysis in psychology. Qualitative Research in Psychology, 3(2), 77-101. https://doi.org/10.1191/1478088706qp063oa

Brew, A. (2013). Understanding the scope of undergraduate research: A framework for curricular and pedagogical decision-making. Higher Education, 66(5), 603-618. https://doi.org/10.1007/s10734-013-9624-x

Cook-Sather, A., \& Felten, P. (2017). Ethics of academic leadership: Guiding learning and teaching. In F. Su \& M. Wood (Eds.), Cosmopolitan perspectives on academic leadership in higher education (pp. 175-191). London: Bloomsbury.

Coombe, L., Huang, J., Russell, S., Sheppard, K., \& Khosravi, H. (2018). Students as partners in action: Evaluating a university-wide initiative. International Journal for Students as Partners, 2(2), 85-95. https://doi.org/10.15173/ijsap.v2i2.3576 
Central Statistics Office (2017). Census 2016 small area population statistics. Retrieved from https://www.cso.ie/en/census/census2016reports/census2016smallareapopulations tatistics/

Curran, R. (2017). Students as partners-good for students, good for staff: A study on the impact of partnership working and how this translates to improved student-staff engagement. International Journal for Students as Partners, 1(2). https://doi.org/10.15173/ijsap.v1i2.3089

Faridi, Z., Grunbaum, J. A., Sajor Gray, B., Franks, A., \& Simoes, E. (2007). Community-based participatory research: Necessary next steps. Preventing Chronic Disease, 4(3). Retrieved from https://www.ncbi.nlm.nih.gov/pmc/articles/PMC1955426/

Felten, P., Bagg, J., Bumbry, M., Hill, J., Hornsby, K., Pratt, M., \& Weller, S. (2013). A call for expanding inclusive student engagement in SoTL. Teaching and Learning Inquiry: The ISSOTL Journal, 1(2), 63-74. https://doi.org/10.20343/teachlearninqu.1.2.63

Gaventa, J. (2002). Exploring citizenship, participation and accountability. IDS Bulletin, 33(2), 1-14. https://doi.org/10.1111/j.1759-5436.2002.tb00020.x

Goodson, L., \& Phillimore, J. (2012). Community research: Opportunities and challenges. In L. Goodson \& J. Phillimore (Eds.), Community research for participation: From theory to method (pp. 3-20). Bristol: Policy Press.

Harwood, V., O'Shea, S., Uptin, J., Humphry, N., \& Kervin, L. (2013). Precarious education and the university: Navigating the silenced borders of participation. International Journal on School Disaffection, 10(2), 23-44. https://doi.org/10.18546/IJSD.10.2.02

Healey, M., Flint, A., \& Harrington, K. (2014). Engagement through partnership: Students as partners in learning and teaching in higher education. York: Higher Education Academy. Retrieved from https://www.advance-he.ac.uk/knowledgehub/engagement-through-partnership-students-partners-learning-and-teachinghigher

Johnson, M., Danvers, E., Hinton-Smith, T., Atkinson, K., Bowden, G., Foster, J., Garner, K., Garrud, P., Greaves, S., Harris, P., Hejmadi, M., Hill, D., Hughes, G., Jackson, L., O’Sullivan, A., O'Tuama, S., Perez Brown, P., Philipson, P., Ravenscroft, S., Rhys, M., Ritchie, T., Talbot, J., Walker, D., Watson, J., Williams, M., \& Williams, S. (2019). Higher education outreach: Examining key challenges for academics. British Journal of Educational Studies, 67(4), 469-491. https://doi.org/10.1080/00071005.2019.1572101

Joyappa, V., \& Martin, D. J. (1996). Exploring alternative research epistemologies for adult education: Participatory research, feminist research and feminist participatory research. Adult Education Quarterly, 47(1), 1-14. https://doi.org/10.1177\%2F074171369604700101

Leydesdorff, L., \& Ward, J. (2005). Science shops: A kaleidoscope of science-society collaborations in Europe. Public Understanding of Science, 14(4), 353-372. https://doi.org/10.1177/0963662505056612

Machin, S. (2006). Social disadvantage and education experiences (OECD Social, Employment and Migration Working Papers No. 32). Paris: OECD Publishing. https://doi.org/10.1787/715165322333

Mannarini, T. (2012) Power and participation in community research: Community profiling in Italy. In L. Goodson \& J. Phillimore (Eds.), Community research for participation: From theory to method (pp. 139-154). Bristol: Policy Press. 
Marquis, E., Black, C., \& Healey, M. (2017). Responding to the challenges of student-staff partnership: The reflections of participants at an international summer institute. Teaching in Higher Education, 22(6), 720-735. https://doi.org/10.1080/13562517.2017.1289510

Matthews, K. E., Dwyer, A., Hine, L., \& Turner, J. (2018). Conceptions of students as partners. Higher Education, 76(6), 957-971. https://doi.org/10.1007/s10734-018$\underline{0257-y}$

McCarry, M. (2012). Who benefits? A critical reflection of children and young people's participation in sensitive research. International Journal of Social Research Methodology, 15(1), 55-68. https://doi.org/10.1080/13645579.2011.568196

Mercer-Mapstone, L., Dvorakova, S., Matthews, K., Abbot, S., Cheng, B., Felten, P., Knorr, K., Marquis, E., Shammas, R., \& Swaim, K. (2017). A systematic literature review of students as partners in higher education. International Journal for Students as Partners, 1(1). https://doi.org/10.15173/ijsap.v1i1.3119

Neary, M._(2010). Student as producer: A pedagogy for the avant-garde? Learning Exchange, 1(1), 1-17.

O'Sullivan, S., O'Tuama, S., \& Kenny, L. (2017). Universities as key responders to education inequality. Global Discourse, 7(4), 527-538. https://doi.org/10.1080/23269995.2017.1400902

Parés, M., Bonet-Martí, J., \& Martí-Costa, M. (2012). Does participation really matter in urban regeneration policies? Exploring governance networks in Catalonia (Spain). Urban Affairs Review, 48(2), 238-271. https://doi.org/10.1177/1078087411423352

Piggot-Irvine, E., Rowe, W., \& Ferkins, L. (2015). Conceptualizing indicator domains for evaluating action research. Educational Action Research, 23(4), 545-566. https://doi.org/10.1080/09650792.2015.1042984

Respond! Housing Association. (2014). The provision of adult and community education in the northside of Cork City. Waterford: Respond! Housing Association. Retrieved from https://www.respond.ie/wpcontent/uploads/2014/03/ProvisionofEducationNCorkCity-Web.pdf

Vortruba, J. C. (1996). Strengthening the university's alignment with society: Challenges and strategies. Journal of Public Service \& Outreach, 1(1), 29-36.

Zhu, Y. (2019). Can participatory action research "empower" participants in adult educational studies? A Marxist-feminist analysis. Canadian Journal for the Study of Adult Education, 31(01). Retrieved from https://cjsae.library.dal.ca/index.php/cjsae/article/view/5454 